\title{
Estudo da Radiação na areia da praia da Areia Preta
}

"Calheiro, D.S.*; Passamai, Jr.J. L.; Orlando, M.T.D"

Calheiro, D.S. ${ }^{1 *} ;$ Passamai, Jr.J.L. ${ }^{*} ;$ Orlando, M. T. D. ${ }^{2}$

1 Departamento de Química e Física, Universidade Federal do Espírito Santo, Alegre, ES, Brasil. 2 Departamento de Física, Universidade Federal do Espírito Santo, Vitória, ES, Brasil.

*e-mail: danielcalheiro@gmail.com

\section{Resumo}

A praia da Areia Preta em Guarapari/ES, apresenta uma quantidade visível do mineral monazita junto com a areia. Sendo assim, foi feito em toda a extensão da faixa de areia um levantamento radiométrico e foi possível observar que: na extensão da praia na faixa da areia utilizada pelos banhistas existem pontos onde há concentrações de oxido de tório juntamente com a areia monazítica. A realização das medidas foram feitas utilizando o contador Geiger $\mathrm{e}$ um ciclocomputador, pode-se concluir que existe uma movimentação da radiação durante os meses do ano ao longo de toda praia.

\begin{abstract}
The Beach Areia Preta in Guarapari / ES, a noticeable amount of monazite mineral along with the sand. Therefore, it was done in the entire length of one track sand radiometric survey and it was observed that: the length of the beach sand in the range used by swimmers points where there are concentrations of thorium oxide along with monazite sand. Carrying out the measurements were made using the Geiger counter, and a cycling computer, it can be concluded that there is a movement of radiation during the months of the year along the entire beach.
\end{abstract}

Keywords (Palavras chaves): Monazita, Radioatividade, Óxido de Tório.

\section{Introdução}

No presente trabalho foi feito medição da radioatividade da areia da praia de Areia Preta. Foi observado que a faixa escura de areia (monazita) foi movimentada pela maré ao longo de toda faixa de areia utilizada pelos banhistas. Foram realizadas medidas a cada 15 adias aproximadamente, durante os meses de Março de 2016 até Maio de 2016, adotamos o sentido de medição norte-sul.

\section{Apresentação dos resultados}

Após a primeira medida realizada, foi feita foi possível constatar que tivemos picos de grande intensidade cerca de $50 \mathrm{~Bq}$, entre 270 metros até 310 metros do inicio da praia, o restante ficou em níveis bem abaixo.

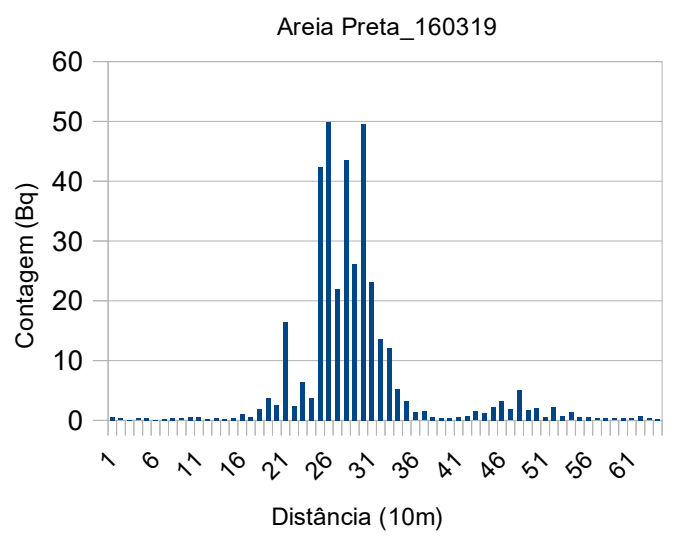


Fizemos uma segunda medida e verificamos que o pico da segunda concentração de radiação havia se deslocado para esquerda em aproximadamente 10 metros e houve um aumento na atividade chegando a próximo de $60 \mathrm{~Bq}$.

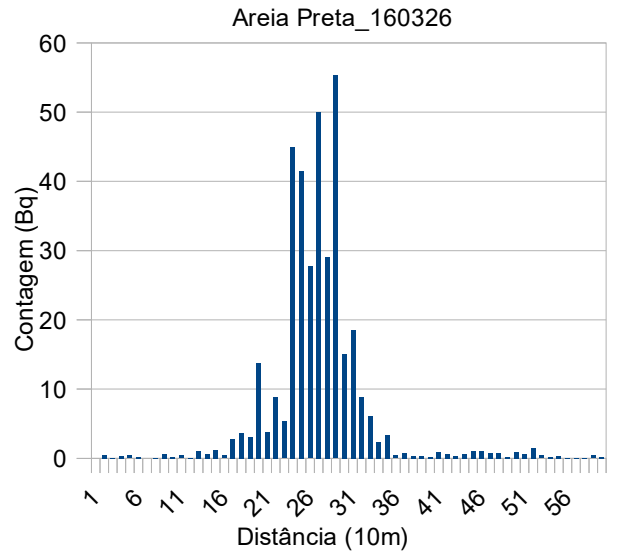

$\mathrm{Na}$ próxima medida realizada foi verificado um acréscimo de radiação em aproximadamente entre 250 metros e 300 metros.

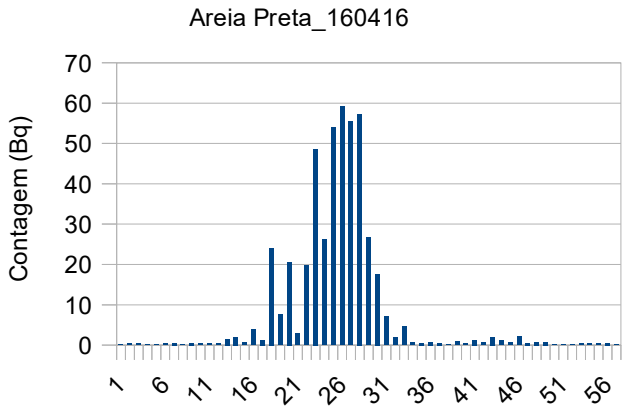

Distância(10m)

Verificamos na medida seguinte uma diminuição da radiação nos picos mencionados anteriormente e uma queda na contagem da intensidade para próximo de $23 \mathrm{~Bq}$.

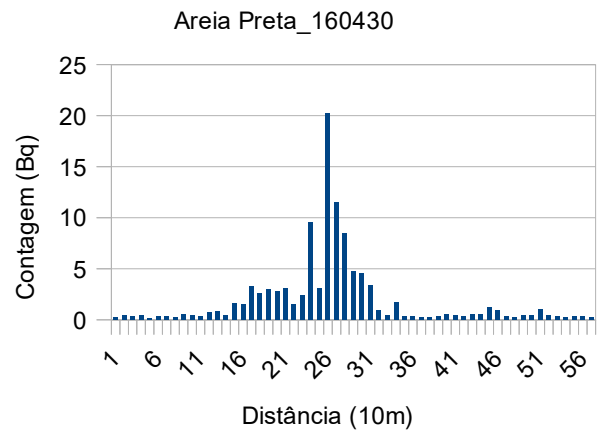

Na medida realizada em 15/05/16 foi observado um acréscimo um pouco mais que o dobro da medida anterior.

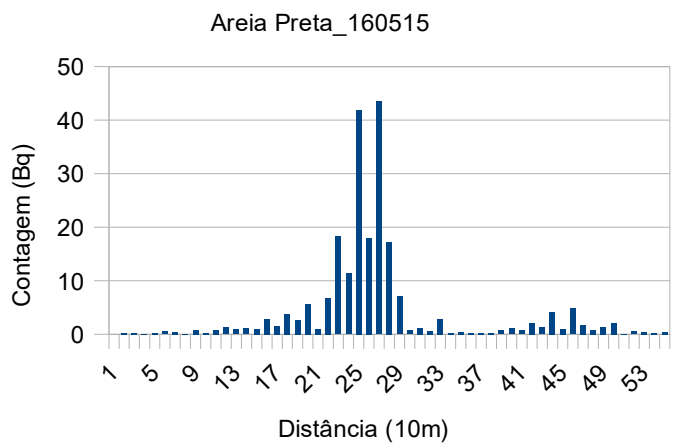

$\mathrm{Na}$ medida realizada em 26/05/16 verificamos uma queda brusca na intensidade da radiação e a presença de radiação em pontos antes não observados, com a marca de 170 metros e 530 metros da faixa de areia utilizada pelos banhistas.

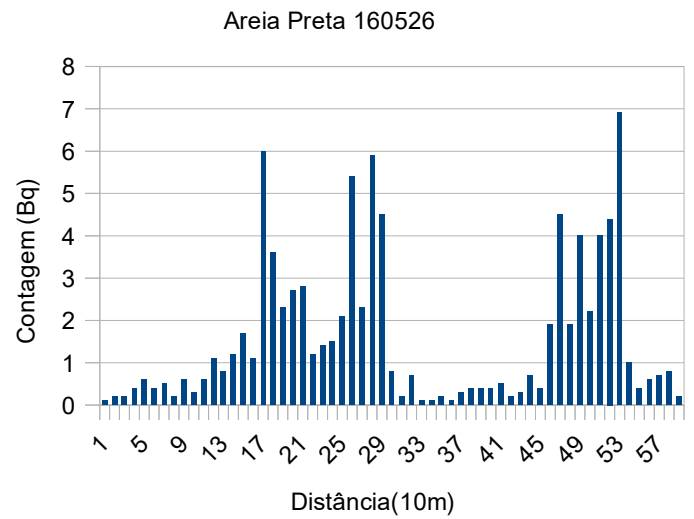

\section{Conclusões}

Em nossos estudos está sendo verificado que a radioatividade está claramente se movimentando pela faixa de areia utilizada pelos banhistas e que a maré que atua na praia da areia preta é uma das responsáveis por esse movimento.

\section{Referências}

FUJINAMI, N.; T. KOGA, T.; MORISHIMA. H. EXTERNAL EXPOUSURE RATES FROM TERRESTRIAL RADIANTION AT GUARAPARI AND MEAIPE IN BRAZIL. 1999.

VASCONCELOS, D.C, et al. MODELLING NATURAL RADIOACTIVITY IN SAND 
BEACHES OF GUARAPARI, ESPÍRITO

SANTO STATE, BRAZIL. 2013. 
